\title{
Redefinición de las TIC en el museo: del discurso invasivo al inclusivo
}

\author{
Redefinition of ICTs in the Museum: \\ from Invasive to Inclusive Discourse
}

Recibido: 28-03-2014

Aceptado: 10-10-2014

\author{
Andrés Adolfo Navarro Newball \\ Universidad Javeriana de Cali, Colombia \\ Facultad de Ingeniería \\ Carrera 118, 18-250 \\ Cali, Colombia \\ anavarro@javerianacali.edu.co \\ Isidro Moreno SÁnChez \\ Departamento de Comunicación Audiovisual y Publicidad II \\ Facultad de Ciencias de la Información \\ Universidad Complutense de Madrid \\ Ciudad Universitaria \\ 28040 Madrid, España \\ ims@ucm.es
}

\begin{abstract}
RESUMEN
Las TIC son inseparables de la museografía in situ e imprescindibles en la museografía en red fija y móvil. En demasiados casos se han instalado prótesis tecnológicas para barnizar de modernidad el espacio cultural, olvidando que la tecnología debe estar al servicio de los contenidos de manera que resulte invisible y perfectamente imbricada con la museografia tradicional. Las interfaces móviles pueden fusionar museo in situ y en red y acompañar a las personas más allá del espacio físico. Esa fusión debe partir de una base de datos narrativa y abierta a obras materiales e inmateriales de otros museos de manera que no se trasladen las limitaciones del museo físico al virtual. En el museo in situ tienen sentido las instalaciones hipermedia inmersivas que faciliten experiencias culturales innovadoras. La interactividad (relaciones virtuales) debe convivir con la interacción (relaciones fisicas y personales) y estar al servicio de todas las personas, partiendo de que todas, todos tenemos limitaciones. Trabajar interdisciplinarmente ayuda a comprender mejor el museo para ponerlo al servicio de las personas.
\end{abstract}

Palabras Clave: Accesibilidad, Museografia hipermedia, Bases de datos narrativas, TIC.

\begin{abstract}
ICTs are inseparable from on-site museology and are essential in mixed and mobile network museography. In too many cases, the cultural space has been varnished of modernity by installing technological prostheses, apparently, forgetting that technology must be at the service of the content so that it is invisible and perfectly blended with traditional museography. Mobile interfaces can merge on-site and network museum and accompany people beyond the physical space. That merger should start from a narrative database open to tangible and intangible works from other museums in a way the limitations of the physical museum are not taken to the virtual one. In the on-site museum, hypermedia immersive facilities make sense by aiding innovative cultural experiences. Interactivity (virtual relationships) must live together with the interaction (physical and personal relationships) and be at the service of all people, considering that we all have limitations. Working interdisciplinary helps us to better understand the museum in order to put it at the service of the people.
\end{abstract}

KeY words: Accesibility, Hypermedia museography, ICTs, Narrative databases. 


\section{Redefinición crítica de las TIC en el museo}

Asensio y Asenjo (2011: 37) destacan la importancia mediadora de la tecnología entre el mensaje patrimonial y las personas usuarias. Pocas personas dudan hoy de que las TIC son inseparables de la museografía in situ e imprescindibles en la museografía en red fija y móvil. Después de un primer estadio marcado por la tecnofobia y la tecnofilia, se produjo otro de expansión con la llegada del tercer milenio. Esa tecnoeuforia se frenó con la crisis de los llamados países desarrollados. Sin medios para la cultura y la investigación, se imponía mirar al futuro y reflexionar sobre el modelo de museografía que imbrique las TIC y una redefinida museografía tradicional.

"Futuro incierto y desconocido pero que seguro será diferente, basado en una mayor participación de los ciudadanos y en el respeto a la diversidad y a la diferencia multiétnica y multicultural, dentro de un contexto global de sostenibilidad del patrimonio cultural y natural. Para poder acercarnos a ese futuro imaginado hay que partir del museo real" (Azuar 2013: 15-16).

Y partir del museo real conlleva una redefinición crítica de las interactividades e interacciones que se producen con sus públicos.

"Mientras que para el estudio de la interacción es necesario articular conceptos provenientes de la psicosociología y antropología cultural hacia el respeto de la diversidad en el armado de la subjetividad (e identidad) de la persona que aprende; para la interactividad, se prestará atención a combinar los avances tecnológicos del hardware y software con los diseños didácticos y los lenguajes simbólicos que presentan las TIC a fin de facilitar una navegación y lectura que posibilite la comprensión y transferencia de los aprendizajes distribuidos por las TIC" (Fainholc 2004: 1).

Comenzando por el continente y parafraseando a Sudjic (2007), parece que se ha pasado del "templo de las musas" al "templo del poder". Se persigue el deslumbramiento con el continente $y$, sin embargo, el contenido sigue siendo el gran olvidado. En demasiados casos se han instalado prótesis tecnológicas para barnizar de modernidad el espacio cultural, olvidando que la tecnología más eficaz es la que resulta invisible.

La descontextualización de las piezas que se produce en el museo las condena a una muerte dulce, pero muerte. Darles vida para que interaccionen con las personas, para que sigan levantando pasiones, continúa siendo el gran reto museográfico. Como también sigue siendo un gran reto museográfico aprovechar esa descontextualización para inducir a la reflexión sobre cualquier tipo de obra. Por ejemplo, la Real Academia de Bellas Artes de San Fernando ha introducido en sus salas obras de videocreación de Bill Viola (Fig. 1) como manera de incitar a la sorpresa, a la reflexión, al goce.

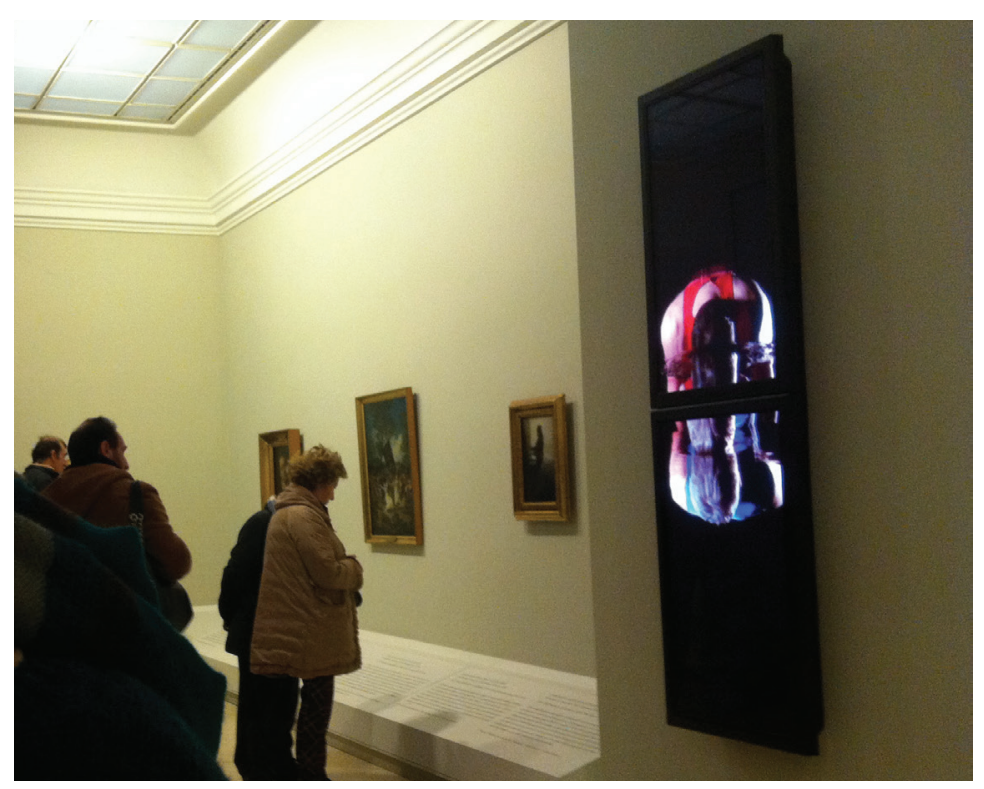

Fig. 1. Videoinstalación de Bill Viola en la Real Academia de Bellas Artes de San Fernando de Madrid. Fotografía: Isidro Moreno. 
En esas interacciones e interactividades con los públicos hay que pensar en todas las personas, partiendo de la premisa de que todas tienen limitaciones. Hay que tener presentes los principios de ergonomía y de diseño universal (Lidwell; Holden y Butler 2010) para perseguir la accesibilidad física e intelectual completa a obras y espacios culturales (Espinosa Ruiz 2010).

\section{Disfunciones museográficas y metodologías para el cambio}

Rodríguez Sánchez (2012: 2) resume las museologías en interactiva, sociomuseológica, crítica, dialógica, digital, de consumo y museal. Todas ellas han estado presentes en la investigación. A sabiendas de su diversidad, se han buscado elementos compartidos y se han encontrado disfunciones similares alrededor de museos estudiados en todo el mundo. Desde el punto de vista de la utilización de las TIC in situ, destacan los museos de ciencias de Londres y Tokyo. Se resumen algunas de las carencias generales compartidas por la mayoría de las instituciones detectadas en la investigación.

\subsection{Disfunciones discursivas}

En general, las TIC siguen un discurso paralelo. La investigación apunta a que las personas que conciben el discurso general piensan en las TIC como un complemento que añada visos de modernidad al museo, pero no se hace con una visión integradora que convierta el discurso en más comprensible y accesible. La supuesta museografía hipermedia suele repetir los viejos esquemas de folletos y catálogos tradicionales. La única diferencia en ciertos casos es que textos e imágenes son digitales y con un mínimo grado de participación interactiva. Esas disfunciones se acentúan a la hora de integrar los sistemas hipermedia en el discurso museal. El Darwin Centre del National History Museum de Londres, un paradigma de coherencia en la integración de las TIC en el museo, no escapa a los errores comunes como la contaminación sonora entre sistemas.

Son tantas las disciplinas que intervienen en el proceso museográfico actual que la inercia empuja hacia la multidisciplinariedad en lugar de a la interdisciplinariedad, abocando a que cada disciplina siga sus propias metodologías sin pensar en el resto. Ramírez y Rabelo (2010) aclaran que la interdisciplinariedad refleja la necesidad de integración y cooperación para solucionar los complejos problemas que se presentan. Este predominio de la multidisciplinariedad viene inducido porque las distintas disciplinas que intervienen en la museología, especialmente las referidas a las TIC, no suelen involucrarse en el proceso.

\subsection{Tecnología invasiva y opacidad de las piezas}

Esa falta de interdisciplinariedad se refleja en una tecnología visible que busca más deslumbrar que alumbrar el conocimiento. La realidad en algunos casos: una pantalla táctil, imágenes fijas y textos, un sencillo catálogo digital interactivo. Sin embargo, los juegos inmersivos, las simulaciones holográficas, las aplicaciones móviles... permiten acercarse al alma de las piezas, viajar en el tiempo para vivir el contexto y descubrir sus significados; en definitiva, aumentar el conocimiento y a hacerlo accesible. Eso es lo que persigue la investigación $\mathrm{I}+\mathrm{D}+\mathrm{i}$ del grupo Museum $\mathrm{I}+\mathrm{D}+\mathrm{C}$ titulada "Conocimiento aumentado y accesibilidad: la representación museográfica de contenidos culturales complejos". Contenidos culturales complejos son la mayoría para las personas no expertas, pero, incluso para personas expertas, la profundización a través de las TIC les exige redefinir sus conocimientos y profundizar en ellos.

\subsection{Falta de interactividad entre las aplicaciones TIC del museo in situ y del museo virtual}

Analizando las aplicaciones TIC de casi cualquier museo, queda de manifiesto que los sistemas hipermedia in situ no comparten recursos con los sistemas hipermedia on line, pues los museos no disponen de una base de datos narrativa que acoja todos los productos multimedia y multimedia interactivos o hipermedia y los comparta en todos los sistemas TIC. El sistema de bases de datos de la mayoría de los museos españoles, denominado Domus, por ejemplo, no admite productos multimedia ni multimedia interactivos. Si esta base de datos no incorpora esos productos TIC, quiere decir que solo se puede acceder a ellos en el museo in situ o en aplicaciones especiales en la web. 


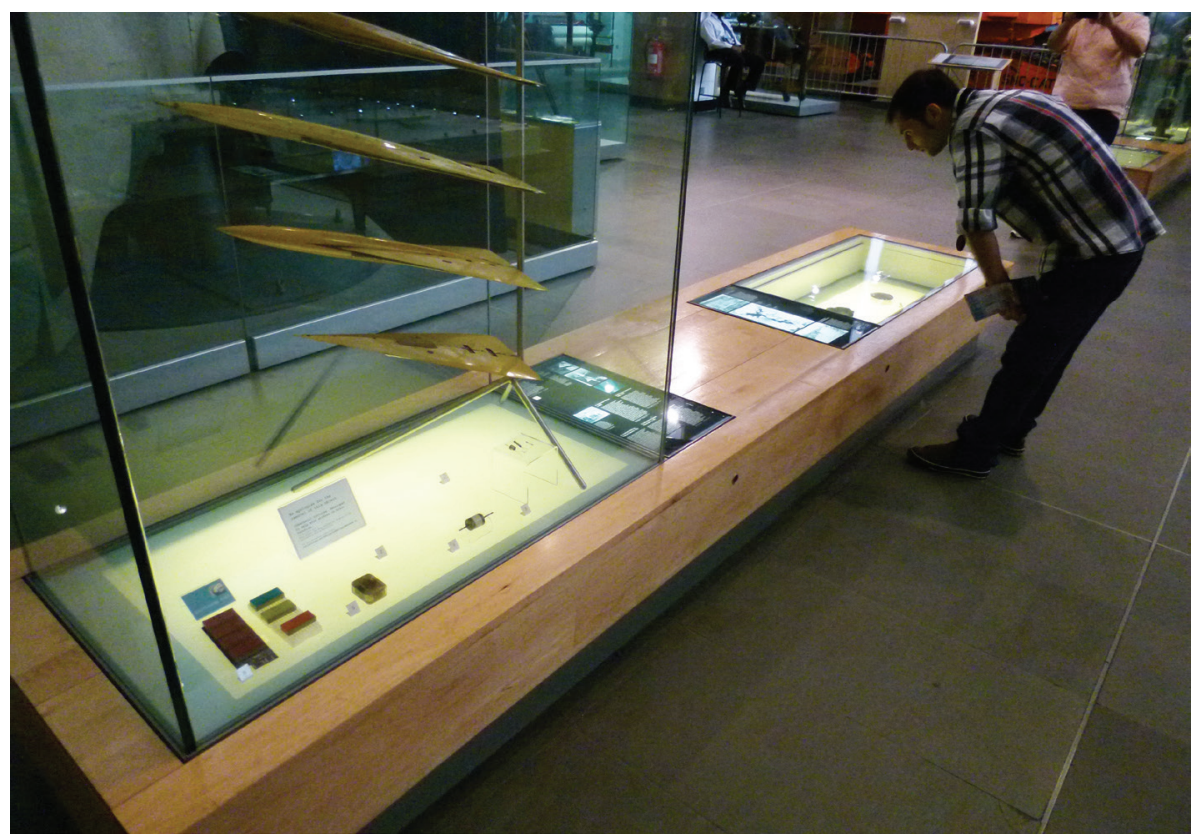

Fig. 2. Vitrina del Science Museum de Londres. Fotografía: Isidro Moreno.

\subsection{Interacción e interactividad entre colecciones de distintos museos}

Utilizando la base de datos DOMUS se ha creado la Red Digital de Colecciones de Museos de España (2014) para integrar en una sola sede web todos los museos que comparten dicha base de datos. No hay duda de que esta aplicación supone un paso significativo para consultar integralmente los museos desde la Red aunque deja visibles sus carencias. Solo se puede acceder a obras de la base de datos DOMUS. Como no es multimedia, el acceso se reduce a imagen fija y a texto. La base de datos DOMUS que se ha tomado como ejemplo y la mayoría de las bases de datos no permiten incluir obras de otros museos. En 2014, aniversario de El Greco, se hizo un extraordinario esfuerzo para presentar el máximo de obras del pintor, sin embargo, ese esfuerzo no se ha llevado a lo virtual. Una vez terminada la efemérides, cada pieza retorna a su lugar de origen. Se pierde así una oportunidad para hacer un museo de "El Griego de Toledo" (así se denominó la mayor exposición del pintor) completo y abierto en el que participen todos los museos y personas que posean obras. Un museo virtual abierto a la investigación con obras navegables de alta calidad, con investigaciones, con reconstrucciones tridimensionales de los retablos, con la digitalización de su biblioteca, con recorridos por el Toledo de El Greco, con su trayectoria vital y geográfica hasta llegar a Toledo... Lo virtual ha quedado reducido a sencillas bases de datos como Visual El Greco (2014).

\subsection{Accesibilidad física e intelectual}

La accesibilidad física a los espacios culturales es una condición sine qua non para la mayoría de los museos de los países más avanzados; sin embargo, sigue siendo una asignatura pendiente en otros muchos países. Sorprende que en una ciudad museo como Cuzco la mayoría de sus museos no sean accesibles físicamente (Moreno 2012). Sin embargo, la accesibilidad física a algunas piezas sigue siendo un problema en casi todos los museos del mundo. Por ejemplo, el Science Museum de Londres tiene algunas vitrinas casi a ras del suelo (Fig. 2).

“Antes de 2013 se elaborarán en todos los Museos nacionales dependientes del Ministerio de Cultura guías adaptadas a personas con discapacidad intelectual y se organizará un mínimo de una visita mensual guiada especializada para tales personas" (Real Patronato sobre Discapacidad 2013: 19).

Este colectivo de personas ha sido uno de los grandes olvidados del museo. Son personas muy 
receptivas que necesitan una transmisión distinta en términos sencillos, que no simples. Esto es aplicable a los sistemas interactivos que más que incorporar versiones en "lectura fácil", deben tenerla en cuenta y huir de la complejidad idiomática. Es fundamental que todas las personas implicadas en la museología y museografía conozcan profundamente todo tipo de limitaciones para aspirar a la accesibilidad universal.

\section{Tecnología, contenidos y accesibilidad}

Hace años, Bill Gates (1996) planteó su visión sobre el futuro de la tecnología. Describió desde dispositivos móviles hasta novedosas formas de interacción. Resaltó la importancia de las aplicaciones para facilitar la accesibilidad de contenidos a través Internet. Indicó cómo "la tecnología debe ser el sirviente y no el amo" (Gates 1996: 238). Describió la revolución de los contenidos: "la nueva tecnología ofrecerá a las personas un nuevo medio para expresarse. Internet abrirá oportunidades artísticas y científicas jamás soñadas a una nueva generación de genios, y también a todos los demás" (Gates 1996: 144). Como ejemplo, expuso Corbis, un sistema de administración de imágenes de alta calidad para museos, bibliotecas y fotógrafos: "Mi idea de que el público considere que vale la pena buscar imágenes está aún por demostrar, pero creo que, con la interfaz adecuada, el servicio atraerá a muchísima gente" (Gates 1996: 247).

Basados en las propias investigaciones del grupo Museum $\mathrm{I}+\mathrm{D}+\mathrm{C}$, se plantean claves para ir del discurso invasivo al inclusivo, teniendo en cuenta aspectos relacionados con la accesibilidad tecnológica. La inaccesibilidad tecnológica está relacionada con la brecha digital y es causada por diferencias socioeconómicas (Cruz-Jesús, Oliveira y Bacao 2012) que impiden a las personas adquirir el dispositivos y servicios tecnológicos. También, se relaciona con limitaciones tecnológicas e intereses mercantilistas.

\subsection{Accesibilidad física - tecnológica}

Se refiere a cómo los dispositivos, aplicaciones y servicios tecnológicos han sido diseñados para interactuar con personas con habilidades físicas diversas. La Figura 3 muestra el aditamento artesanal para una persona con cuadriplejia con nivel en C5 que solo puede mover la articulación del hombro derecho. Este aditamento per-

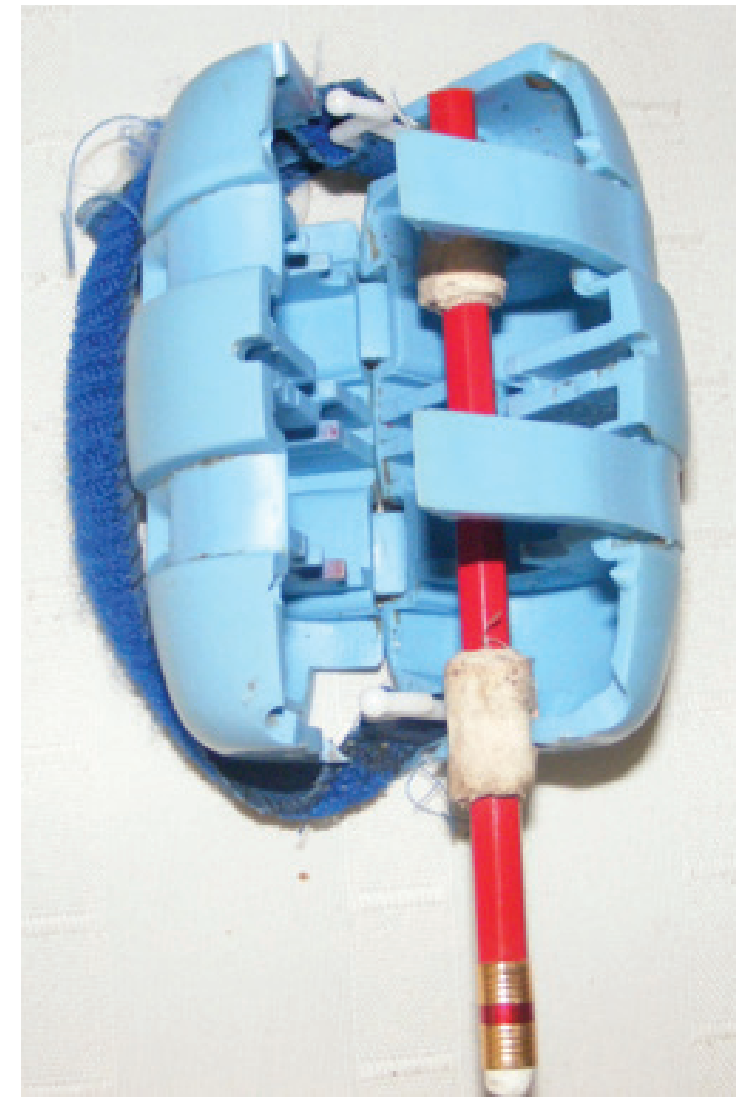

Fig. 3. Accesibilidad física - tecnológica. Foto: V. Contreras.

mitía al usuario presionar las teclas del ordenador pero no impidió el deterioro del hombro.

Gates (1996) habla del acceso a múltiples servicios tecnológicos, pero no discute la diversidad física. Esta es tan grande como las posibles limitaciones y accidentes que pueden tener cada sentido humano. Pensar en soluciones de accesibilidad tecnológica físicas que incluyan a toda la población es fundamental, pero desafortunadamente, complejo. Moreno y Navarro (2013) describen un sistema instalado en el Museo de América de Madrid, que permite a los usuarios vivir la experiencia de excavar una Pirámide Chimú para encontrar sus tesoros. Este proyecto de Museum $\mathrm{i}+\mathrm{D}+\mathrm{C}$ considera la accesibilidad física tecnológica pues permite la interacción de personas de diferentes estaturas; orienta la interacción al uso de los brazos para que el sistema sea accesible a personas que no pueden caminar; permite el uso de ambos brazos para incluir personas zurdas y diestras. Sin embargo, la experiencia se queda corta para usua- 
rios con el tipo de diversidad física descrita en el párrafo anterior.

\subsection{Accesibilidad intelectual - tecnológica}

Se refiere a como los dispositivos, aplicaciones y servicios tecnológicos han sido diseñados para ser entendidos por personas con habilidades cognitivas diversas. La historia de la computación muestra cómo los ordenadores son más usables gracias a las interfaces gráficas de usuario (Press 1990). Sin embargo, definir el nivel de simplicidad adecuado para todos es complejo.

Gates (1996) habla de cómo la tecnología abrirá un mundo de oportunidades. Hoy, herramientas como la WEB 2.0 (Fumero y Roca 2007) permiten a "genios" comunes la creación de contenidos. Nuevas tecnologías permiten la interacción natural (Zhang 2012). El serious game sobre Pirámide Chimú descrito anteriormente usa un sensor de movimiento que permite realizar gestos para excavar y tomar objetos de manera natural. Esta se complementa con una aplicación móvil (Chimú RA) que con realidad aumentada e interactividad táctil es accesible al usuario común y al experto. La narrativa apoya la accesibilidad intelectual tecnológica (Tanenbaum 2011). El proyecto Chimú emula la experiencia de un arqueólogo y evidencia la necesidad de incorporar narrativas adecuadas que faciliten esta accesibilidad. Los videojuegos son herramientas que brindan este tipo de accesibilidad en contextos culturales (Christopoulos 2013).

\subsection{Accesibilidad social - tecnológica}

Se refiere a cómo los dispositivos y servicios tecnológicos han sido utilizados por personas con características socioculturales diversas. Ciertos países bloquean contenidos (Lee 2002) intentando evitar la adopción de perspectivas diferentes. Aquellos que no poseen las marcas tecnológicas "de moda" son excluidos del grupo por Brand Bullying (Pulishuk 2014). La tecnología vista así causa ansiedad (Lee et. al. 2014), adicción (İskender y Akin 2010) y religiosidad (Shachar 2011) que la mistifican (o a su marca) sobre los contenidos. Recuérdese que Gates (2006) afirma que la tecnología debe ser "el sirviente y no el amo".

\subsection{Retos tecnológicos y conceptuales}

Las aplicaciones móviles permiten acercar a los visitantes el espacio museal y llevar parte de la experiencia fuera de ese espacio físico (Tillon, Marchal y Houlier 2011), pero las plataformas para su desarrollo son herméticas y dificultan su portabilidad a otras (Santanchè 2013). Así se favorece el deslumbramiento tecnológico y mercantilista. La realidad es que cualquier dispositivo móvil puede ser utilizado como un ordenador de propósito general siempre que la desarrolladora tenga la voluntad de programarlo. HTML5 ofrece una posible futura salida a este problema (Xinogalos, Psannis y Sifaleras 2012), aunque todavía existen limitaciones como el poder de procesamiento, tamaño de la pantalla, eficiencia de energía y ancho de banda. Chimú RA comenzó funcionando en una sola plataforma móvil. Se eligió la que menos limitaciones ponía al desarrollador y al hardware de acceso. Se es consciente de que mientras no esté disponible en todas las plataformas, se está limitando el acceso a muchas personas.

La realidad aumentada, que con una cámara incorpora contenido digital en imágenes reales, presenta muchos retos y la mayoría de sus aplicaciones demuestran los estados iniciales en que se encuentra su uso (Wei et. al 2012). Chimú RA tuvo que adaptarse para reconocer los textos o cartelas asociadas a los objetos reconocibles dentro de la aplicación (Fig. 4). Esto se debió a las dificultades ligadas al reconocimiento de los objetos expuestos en condiciones de baja iluminación con fondos negros.

La realidad virtual, en donde un visitante está inmerso en un mundo digital simulado, necesita evolucionar en temas de realismo, procesamiento e interactividad colaborativa (Duval y Fleury 2009). Producir sensaciones inmersivas y realistas en sentidos como la visión y la audición y más aún como el tacto, el gusto y el olfato es todavía un reto tecnológico apenas esbozado. La pirámide Chimú utiliza principios de realidad virtual que incluyen la proyección en gran tamaño; sonido envolvente y detección del usuario en el espacio. Sin embargo, evita el uso de lentes o dispositivos que mejorarían el nivel de realismo al coste de producir cansancio y no permite la participación de más de una persona simultáneamente. Este proyecto no busca reemplazar la experiencia real, sino acercarla a las personas que no pueden realizar una excavación in situ.

Todas las tecnologías enunciadas enfrentan el reto de la generación y administración de sus contenidos. Se ve que hoy día se ha democratizado la generación de contenido textual, sonoro 


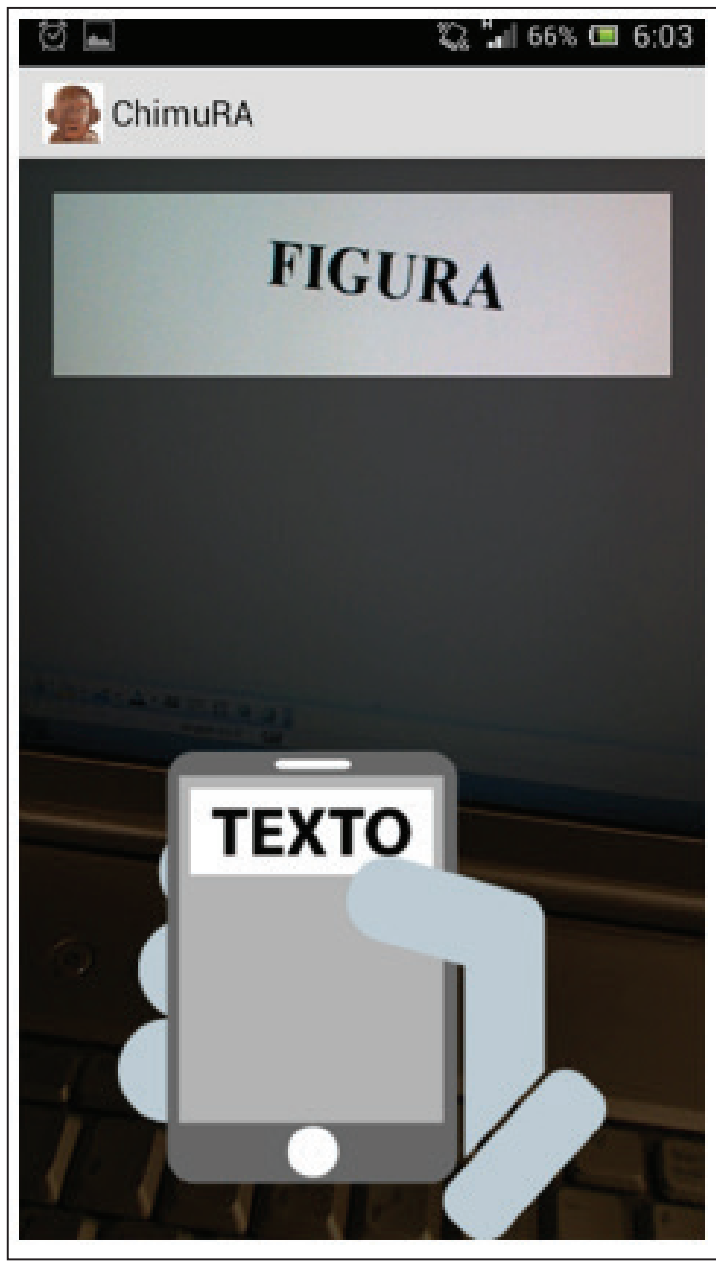

Fig. 4. Detectando objeto a través de una cartela. Imagen: los autores.

y de imágenes y vídeo (Fumero y Roca 2007). Sin embargo, la creación de contenidos que contribuyan a una narrativa museográfica completa requiere todavía el uso de herramientas costosas y difíciles de usar, además de la especialización de tecnólogos, museólogos, programadores, artistas... Las mejores herramientas, aunque ayudan al experto, la mayoría de las veces no permiten la generación rápida de contenidos por parte del usuario común. El proyecto Chimú requirió la unión interdisciplinar de diferentes especializaciones durante una investigación de tres años, lo que sugiere que algunos aspectos de la revolución de los contenidos (Gates 1996), requerirá inevitablemente el trabajo en equipo y la especialización de las personas en algunos aspectos, en especial cuando se trata de modelar contenido cultural o científico complejo.
En cuanto a las disfunciones museográficas debidas a la tecnología, Museum $\mathrm{I}+\mathrm{D}+\mathrm{C}$ evita, en lo posible la tecnología invasiva. La Pirámide Chimú se sitúa en un espacio independiente, pero estratégicamente situado a la salida de una de las salas del Museo de América para que no pase desapercibido a ninguna persona que visite la sala. Chimú RA, en lugar de utilizar códigos visibles, reconoce las cartelas de la pieza.

Un problema mayor, evidenciado en la falta interactividad entre las aplicaciones TIC del museo in situ y del museo virtual y la falta de interacción e interactividad entre colecciones de distintos museos, se debe a la ausencia de una base de datos narrativa. En el proyecto Chimú, se desarrolló una base de datos narrativa que va más allá de las taxonomías utilizadas en los museos y que contempla todo tipos de materiales multimedia y puede incorporar piezas de cualquier colección pública o privada.

La búsqueda de imágenes e información compleja de Corbis (Gates 1996) es una realidad, como lo demuestran proyectos como ArtProject (Google 2014), aunque, conceptualmente sea bastante limitada. Con la base de datos narrativa mencionada sobre la cultura Chimú se intenta resaltar la necesidad de bases de datos narrativas multimedia abiertas capaces de generar museos virtuales que rompan los límites del museo real y, por otra parte, interactúen con los reales completándose y complementándose.

\section{Conclusiones}

No hay ninguna duda de que la tecnología brinda nuevas posibilidades; sin embargo incorporar mecanismos de accesibilidad de la tecnología en sí misma y de ésta relacionada con la diversidad física, social e intelectual dependerá de la atención que los grupos de investigación presten al tema. En algunos casos, habrá que esperar a que la tecnología permita desarrollar la visión de los creativos, en otros, a que las productoras de tecnología unifiquen esfuerzos hacia la inclusión.

Las investigaciones del grupo Museum $\mathrm{i}+\mathrm{D}+\mathrm{C}$ buscan la accesibilidad integral, pero se es consciente de las limitaciones que existen para alcanzarla. Para aumentar el conocimiento y hacerlo accesible es necesario mantener una coherencia científica en todos los desarrollos narrativos en el museo in situ y en red. En el espacio in situ se aboga por sistemas inmersivos capaces de transmitir experiencias científicas de una manera 
atractiva y rigurosa. Los sistemas móviles evitan las prótesis tecnológicas en el espacio museal y permiten trasladar el museo a donde desee la persona.

La museografía hipermedia ha de fusionarse con la museografía tradicional partiendo de una museología integral que las aúne en el museo real y en el virtual. La base de datos narrativa multimedia y abierta debe compartir todos los recursos en ambos museos. El museo virtual no ha de ceñirse a las piezas del museo real, sino completarse con las colecciones de otros museos $\mathrm{y}$ coleccionistas.

Las investigaciones en museología y museografía han de ser interdisciplinares. Sin embargo, predomina lo multidisciplinar. Algunas especialidades no desean involucrarse en el discurso museal completo y prefieren restringirse a su labor parcial. En otros casos, los museólogos prefieren esa multidisciplinariedad para que el resto de especialidades tenga una labor puramente complementaria.

La interactividad debe completarse y complementarse con la interacción en el museo in situ. En el museo virtual siempre se dan relaciones tecnológicas, pero esa interactividad no debe circunscribirse exclusivamente a la base de datos narrativa, sino abrirse a la interactividad interacción con las personas que trabajan en el museo y, por supuesto, con el resto que lo disfrutan.

\section{Notas}

1. Este artículo se enmarca dentro de la investigación $\mathrm{I}+\mathrm{D}+\mathrm{i}$ "Conocimiento aumentado y accesibilidad: la representación museográfica de contenidos culturales complejos" (Referencia: HAR2011-25953) del grupo de investigación Museum I $+\mathrm{D}+\mathrm{C}$, Laboratorio de Cultura Digital y Museografía Hipermedia de la Universidad Complutense de Madrid con la colaboración del proyecto MOMU (Modelo Interactivo para Museos) de la Universidad Javeriana de Cali, Colombia, y ha sido financiado por el Ministerio de Economía y Competitividad y por el Ministerio de Educación, Cultura y Deporte. Cuenta con la colaboración especial del Museo de América de Madrid, y los apoyos de la Fundación ITMA, Museo Convento Santo Domingo-Qorikancha del Cusco, Optimedia, Schwann Beijing, Telefónica TIC y el grupo de artes escénicas El Tinglao que integra a personas con diversidad funcional. Andrés Adolfo Navarro Newball es el investigador responsable de la tecnología del proyecto e Isidro Moreno Sánchez, el IP del mismo.

\section{REFERENCIAS BibLiográFicas}

Asensio, M.; Asenjo, E. (2011): Lazos de luz azul. Museos y Tecnologías 1, 2 y 3.0. UOC, Barcelona.

Christopoulos, D.; Mavridis, P.; Andreadis, A.; Karigiannis, J.N. (2013): Digital storytelling within virtual environments: "the battle of thermopylae". Transactions on Edutainment IX (Zhigeng Pan, Adrian David Cheok, Wolfgang Müller, Fotis Liarokapis, eds.). Springer-Verlag, Berlin, Heidelberg: 29-48.

Cruz-Jesús, F.; Oliveira, T.; BaCaO, F. (2012): Digital divide across the European Union. Inf. Manage. 49, 6 (October 2012): 278-291. [URL: htttp://dx.doi.org/10.1016/j.im.2012.09.003]. Acceso el 13/02/2014.

Duval, T.; Fleury, C. (2009): An asymmetric 2D Pointer/3D Ray for 3D interaction within collaborative virtual environments. Proceedings of the 14th International Conference on $3 D$ Web Technology (Web3D '09), Stephen N. Spencer (Ed.), ACM, New York, NY, USA: 33-41. [URL: http://doi.acm. org/10.1145/1559764.1559769]. Acceso el 10/02/2014.

Espinosa Ruiz, A. (2010): La accesibilidad física e intelectual de todo tipo de público al patrimonio cultural. Boletín de interpretación, 6. [URL: http://interpretaciondelpatrimonio.com/boletin/index.php/boletin/article/view/82/0]. Acceso el 20/03/2014.

FAINHOLC, B (2004): La interactividad en las Tecnologías de la Información y la Comunicación y su diferencia conceptual con la interacción social. UNLP-CEDICPROE, Buenos Aires [URL: www.cediproe.org. ar/new/historial1.php]. Acceso el 20/03/2014.

Fumero, A.; RocA, G. (2007): Web 2.0. Fundación Orange, Madrid. [URL: www.vinv.ucr.ac.cr/docs/divulgacion-ciencia/libros-y-tesis/web-def-completo.pdf]. Acceso el 20/03/2014.

Gates, B. (1996): Camino al Futuro. McGraw-Hill - Interamericana de España, S. A. U., Madrid. 
Google (2014): ArtProject. Cultural Institute, Google. [URL: www.google.com/culturalinstitute/project/artproject?hl=es]. Acceso el 20/03/2014.

İsKender, M.; AKIN, A. (2010): Social self-efficacy, academic locus of control, and internet addiction. Comput. Educ. 54, 4 (May 2010): 1101-1106. [URL: http://dx.doi.org/10.1016/j.compedu.2009.10.014. Acceso el 15/02/2014.

Lee, Y.K.; Chang, C.T.; Lin, Y.; Cheng, Z.H. (2014): The dark side of smartphone usage: Psychological traits, compulsive behavior and technostress. Comput. Hum. Behav. 31 (February 2014): 373-383. [URL: http://dx.doi.org/10.1016/j.chb.2013.10.047]. Acceso el 11/02/2014.

Lidwell, W.; Holden, K. \& Butler, J. (2010): Universal Principles of Design, Revised and Updated: 125 Ways to Enhance Usability, Influence Perception, Increase Appeal, Make Better Design Decisions, and Teach through Design. Rockport Publishers, Beverly, Massachusetts [URL: sse.tongji.edu.cn/liangshuang/hci2013spring/readings/universal-principles-of-design.pdf]. Acceso el 20/03/2014.

Moreno SÁnchez, I. (2012): Conocimiento aumentado y accesibilidad en los museos del Cusco. Chasqui, 117, p. 48 - 54. [URL: 186.5.95.155:8080/jspui/123456789/359]. Acceso el 20/03/2014.

Moreno Sánchez, I.; Navarro Newball, A. (2013): Comunicación cultural y TIC: La representación accesible de la cultura Chimú. Historia y Comunicación Social, 18: 541-554. [http://dx.doi.org/10.5209/ rev_HICS.2013.v18.43987]. Acceso 5/02/2014.

Press, L. (1990): Personal computing: Windows, DOS and the MAC. Commun. ACM 33, 11 (November 1990): 19-26. [URL: http://doi.acm.org/10.1145/92755.92783]. Acceso el 14/02/2014.

Pulishuk, M. (2014): El explosivo fenómeno del Bullying de marcas. [URL: http://mpolishuk.wordpress. com/2012/08/20/el-explosivo-fenomeno-del-bullying-de-marcas]. Acceso el 20/03/2014.

Ramírez Paseiro, S. E.; Rabelo Mari, E. (2010): La interdisciplinariedad en las Ciencias en el primer milenio. Órbita Científica, 16 (58), 8 pp. [URL: www.ucpejv.rimed.cu]. Acceso el 20/03/2014.

Real Patronato Sobre Discapacidad (2011): Estrategia integral española de cultura para todos. Accesibilidad a la cultura para las personas con discapacidad. Ministerio de Cultura, Madrid. [URL: www.msssi. gob.es/ssi/discapacidad/docs/estrategia_cultura_para_todos.pdf]. Acceso el 20/03/2014.

Red Digital De Colecciones De Museos De España (2014): [URL: ceres.mcu.es/pages/ SimpleSearch?index=true]. Acceso el 20/03/2014.

Rodríguez SÁnchez, K. (2012): Las musas del siglo XXI: indicios del cambio educativo museal. En: Revista de Actualidades Investigativas en Educación, 12 (2): 1-15. [URL: revista.inie.ucr.ac.cr/uploads/ tx_magazine/musas-principio-siglo-xxi-indicios-cambio-educativo-museal-rodriguez.pdf]. Acceso el 20/03/2014.

Santanché, A.; Boulanger, R.; Viana, G.; Panaggio, R.; Melo, B.; Aboud, H. (2013): Mobile development using web technologies focusing on games. Proceedings of the 19th Brazilian symposium on Multimedia and the web (WebMedia '13). ACM, New York, NY, USA: 13-14. [URL: http://doi.acm. org/10.1145/2526188.2528541]. Acceso el 12/02/2014.

Shachar, R.; Erdem, T.; Cutright, K.m. Y Fitzsimons, G.J. (2011): Brands: The Opiate of the Nonreligious Masses? Marketing Science 30, 1 (January 2011): 92-110. [URL: http://dx.doi.org/10.1287/ mksc.1100.0591]. Acceso el 3/02/2014.

SudJIC, D. (2007): La arquitectura del poder. Ariel, Barcelona.

Tanenbaum, J. (2011): Being in the story: readerly pleasure, acting theory, and performing a role. Proceedings of the 4th international conference on Interactive Digital Storytelling (ICIDS'11) ( Mei Si, David Thue, Elisabeth André, James C. Lester, Joshua Tanenbaum, eds.), Springer-Verlag, Berlin, Heidelberg: 55-66. [URL: http://dx.doi.org/10.1007/978-3-642-25289-1_7]. Acceso el 10/02/2014.

Tillon, A.B.; Marchal, I.; Houlier, P. (2011): Mobile augmented reality in the museum: Can a lace-like technology take you closer to works of art? Proceedings of the 2011 IEEE International Symposium on Mixed and Augmented Reality--Arts, Media, and Humanities (ISMAR-AMH '11). IEEE Computer Society, Washington, DC, USA: 41-47. [URL:http://dx.doi.org/10.1109/ISMAR-AMH.2011.6093655. Acceso el 5/02/2014.

Visual El Greco (2014): [URL: www.visualelgreco.es/index.htm]. Acceso el 20/03/2014. 
Wei, C.; Wang, C.N.; Ramnath, R.; Ramanathan, J. (2012): Examining the practical challenges of an Augmented Reality cyber-infrastructure framework. Proceedings of the 27th Annual ACM Symposium on Applied Computing (SAC '12). ACM, New York, NY, USA: 531-536. [URL: http://doi.acm. org/10.1145/2245276.2245378]. Acceso el 10/03/2014.

Xinogalos, S.; Psannis, K. E.; Sifaleras, A. (2012): Recent advances delivered by HTML 5 in mobile cloud computing applications: a survey. Proceedings of the Fifth Balkan Conference in Informatics (BCI '12). ACM, New York, NY, USA: 199-204. [URL: http://doi.acm.org/10.1145/2371316.2371355]. Acceso el 28/02/2014.

ZHANG, Z. (2012): Microsoft Kinect Sensor and Its Effect. IEEE MultiMedia 19, 2 (April 2012): 4-10. [URL: http://dx.doi.org/10.1109/MMUL.2012.24]. Acceso el 14/02/2014. 